\title{
Assessing the ecological impacts of invasive species based on their functional responses and abundances
}

\author{
Ciaran Laverty 10 - Kyle D. Green · Jaimie T. A. Dick • Daniel Barrios-O'Neill • \\ Paul J. Mensink • Vincent Médoc • Thierry Spataro • Joe M. Caffrey • \\ Frances E. Lucy • Pieter Boets • J. Robert Britton · Josephine Pegg • \\ Cathal Gallagher
}

Received: 28 June 2016/ Accepted: 30 January 2017/Published online: 8 February 2017

(C) The Author(s) 2017. This article is an open access publication

\begin{abstract}
Invasive species management requires allocation of limited resources towards the proactive mitigation of those species that could elicit the highest ecological impacts. However, we lack predictive capacity with respect to the identities and degree of ecological impacts of invasive species. Here, we combine the relative per capita effects and relative field abundances of invader as compared to native species into a new metric, "Relative Impact Potential" (RIP), and test whether this metric can reliably predict high impact invaders. This metric tests the impact of invaders relative to the baseline impacts of natives on the broader ecological community. We first derived
\end{abstract}

C. Laverty · K. D. Green · J. T. A. Dick ( () .

D. Barrios-O’Neill · P. J. Mensink

Institute for Global Food Security, School of Biological

Sciences, Queen's University Belfast, MBC, 97 Lisburn

Road, Belfast, N. Ireland

e-mail: j.dick@qub.ac.uk

C. Laverty · K. D. Green · F. E. Lucy

Centre for Environmental Research, Innovation \&

Sustainability, Institute of Technology Sligo, Ash Lane,

Co. Sligo, Ireland

V. Médoc $\cdot$ T. Spataro

Institute of Ecology and Environmental Sciences,

Université Pierre Et Marie Curie (Paris 6), 75005 Paris,

France

J. M. Caffrey

INVAS Biosecurity, 6 Lower Ballymount Road,

Walkinstown, Dublin 12, Ireland the functional responses (i.e. per capita effects) of two ecologically damaging invasive fish species in Europe, the Ponto-Caspian round goby (Neogobius melanostomus) and Asian topmouth gudgeon (Pseudorasbora parva), and their native trophic analogues, the bullhead (Cottus gobio; also C. bairdi) and bitterling (Rhodeus amarus), towards several prey species. This establishes the existence and relative strengths of the predator-prey relationships. Then, we derived ecologically comparable field abundance estimates of the invader and native fish from surveys and literature. This establishes the multipliers for the above per capita effects. Despite both predators having known

\author{
P. Boets \\ Provinciaal Centrum Voor Milieuonderzoek, \\ Godshuizenlaan 95, 9000 Ghent, Belgium \\ J. R. Britton · J. Pegg \\ Department of Life and Environmental Sciences, Faculty \\ of Science and Technology, Bournemouth University, \\ Dorset BH12 5BB, UK \\ C. Gallagher \\ Inland Fisheries Ireland, 3044 Lake Drive, Citywest \\ Business Campus, Dublin, Ireland
}


severe detrimental field impacts, their functional responses alone were of modest predictive power in this regard; however, incorporation of their abundances relative to natives into the RIP metric gave high predictive power. We present invader/native RIP biplots that provide an intuitive visualisation of comparisons among the invasive and native species, reflecting the known broad ecological impacts of the invaders. Thus, we provide a mechanistic understanding of invasive species impacts and a predictive tool for use by practitioners, for example, in risk assessments.

Keywords Functional response - Invasive species · Ecological impact · Neogobius melanostomus . Pseudorasbora parva

\section{Introduction}

Management of invasive species is one of our greatest global challenges, due to their perceived idiosyncratic nature and their continuing ecological and economic damage (Simberloff et al. 2013). In particular, scientists and practitioners have been frustrated by a lack of predictive methodologies to reliably identify potentially damaging invaders and their likely degree of ecological impact (i.e. measureable changes in populations of affected species; see Dick et al. 2014). Presently, invaders may be prioritised for management based on their documented impacts elsewhere, that is, their invasion history (Kulhanek et al. 2011; Ricciardi et al. 2013); however, this precludes the assessment of novel or potential invaders, or those for which relevant data are missing or scarce. Further, several hypotheses have emerged attempting to explain the mechanisms underlying the success and impacts of invaders, but many of these have not yet received rigorous testing (Ricciardi et al. 2013), and species-trait based predictive methods are notoriously unconvincing (Dick et al. 2014). We thus urgently require a mechanistic understanding of invader impacts that translates into a useful predictive methodology if early warning and rapid response approaches-such as those dictated by recent EU legislation on Invasive Alien Species-are to be developed and applied to this pernicious problem.

Previously, invasion ecologists (Parker et al. 1999) described the impact of an invasive species as:
$I=R \times A \times E$

where the total impact $(I)$ of the invader is a function of its range $(R)$, abundance $(A)$, and its per capita effect $(E)$. This has, however, received little application in invasion ecology, in particular because measures of per capita effects have been lacking (Dick et al. 2014). However, as detailed by Dick et al. (2013, 2014), the per capita effect of an invasive species may be quantified by its 'Functional Response' (FR), a classic metric used in ecology to describe and quantify the per capita effect of a predator on its prey as the density of the prey increases (Solomon 1949; Holling 1959a,b), but which can be applied across all taxonomic and trophic groups in any consumer/resource interaction (Dick et al. 2014, 2017). Together with the 'Numerical Response' (NR), which describes the change in a predator population as the density of prey increases, this forms the 'Total Response' (TR), such that:

$\mathrm{TR}=\mathrm{FR} \times \mathrm{NR}$

Functional responses (FRs) alone have been shown to predict the damaging impact of some invaders (e.g. bloody red shrimp Hemimysis anomala, Dick et al. 2013; largemouth bass Micropterus salmoides, Alexander et al. 2014a, b; killer shrimp Dikerogammarus villosus, Dodd et al. 2014; golden apple snail Pomacea canaliculata $\mathrm{Xu}$ et al. 2016); these invasive consumers show significantly higher FRs than trophically analogous native consumers. However, ecological impacts, such as by predators, will be the product of their per capita effects and the number of individuals having those effects; both must be quantified to elucidate overall effects. Further, invaders with high FRs but low abundance, or low FRs but high abundance, may also have large ecological impacts, but only consideration of both per capita effects and abundance would reveal their potential impacts. While the measurement of functional responses is relatively straightforward (e.g. Dick et al. 2013), the numerical response is a much more nebulous measure and somewhat laborious, and we propose that simple predator abundance $(\mathrm{AB})$ estimates can be used as a proxy, thus giving the "Impact Potential" (IP) of an invader as:

$\mathrm{IP}=\mathrm{FR} \times \mathrm{AB}$

We thus propose that the Impact Potential (IP) of an invader is the product of its Functional Response 
(FR; per capita interaction strength) and ABundance ( $\mathrm{AB}$; number of interacting individuals). Further, however, as this absolute value is rather meaningless with respect to the baseline predatory impact of existing native analogous predators, the calculation is repeated for the native(s), allowing a standardised comparison of invader versus native IP values, or Relative Impact Potential (RIP). To investigate the efficacy of Relative Impact Potential to predict invader effects, we calculated the RIP values using empirically-derived estimates of the functional responses of two highly invasive freshwater fish and compared them with RIP values for their native trophic analogues. Abundances were estimated from surveys and the literature. We chose the high-impact invasive round goby, Neogobius melanostomus, a Ponto-Caspian fish which has invaded freshwaters in Europe (Manné et al. 2013) and N. America (Jude et al. 1992), leading to drastic declines in native aquatic invertebrates and fish (Barton et al. 2005; Pagnucco and Ricciardi 2015). We first experimentally derived the functional responses of $N$. melanostomus and a native trophic analogue, the European bullhead Cottus gobio, towards two benthic macroinverebrates, the amphipod Echinogammarus berilloni and the isopod Asellus aquaticus. We then use available field abundance data for these two fish species to calculate Relative Impact Potential (RIP) as per Eq. (3) above and present an "RIP biplot" as a visual representation of the impact comparison. We supplement this with FR data from $N$. melanostomus and another native comparator, the mottled sculpin Cottus bairdi, towards Gammarus prey (see Dubs and Corkum 1996), again with available abundance data. Then, we repeat this exercise with the highly invasive and ecologically damaging topmouth gudgeon, Pseudorasbora parva, an Asian fish which has also invaded European waters (Britton et al. 2010; Gozlan et al. 2010), and its native analogue the European bitterling, Rhodeus amarus, towards two prey species, Daphnia magna and Chironomus spp.. We stress that this exercise is to compare and quantify the impacts of the invaders on the broader prey community and it is not intended to examine any interaction, such as competition, among the invader and native fishes (but see Dick et al. 2014, 2017).

\section{Materials and methods}

Species collection and husbandry: Neogobius melanostomus and Cottus gobio

In October 2014, invasive N. melanostomus were collected from the Moselle River at Koenigsmacker (Moselle, N 49 $24^{\prime} 14.573^{\prime \prime}$ E $6^{\circ} 15^{\prime} 24.324^{\prime}$ ), while native $C$. gobio and the amphipod E. berilloni were obtained from the Lunain River near Nonville (Ile-deFrance, N 48 $17^{\prime} 22.111^{\prime \prime}$ E $2^{\circ} 47^{\prime} 23.774^{\prime \prime}$ ). Isopods, $A$. aquaticus, were collected from a small pond at the CEREEP field station at St. Pierre Lès Nemours, where the FR experiments were carried out (CEntre de Recherche en Ecologie Experimentale et Predictive, Seine et Marne, N 48 $17^{\prime} 14.4924^{\prime \prime}$ E $002^{\circ} 40^{\prime} 46.6536^{\prime \prime}$ ). Amphipods and isopods were chosen as common prey items of these fish species (see Welton et al. 1991; Dubs and Corkum 1996; Corkum et al. 2004; Barton et al. 2005). Fishes were obtained using electrofishing (Hans Grassl IG600 type, Aquaculture, France), while prey species were collected by kick sampling (E. berilloni) and dip netting (A. aquaticus). All species were then transferred in source water to the CEREEP field station. Fishes used in the experiment below were size matched as closely as possible with respect to total length (TL) and gape height $(\mathrm{GH})(\mathrm{TL} \mathrm{cm} \pm$ S.E., goby $=8.6 \pm$ 0.22 , bullhead $=8.0 \pm 0.17, \quad \mathrm{GH} \quad \mathrm{mm} \pm$ S.E., goby $=6.16 \pm 0.25$, bullhead $=6.25 \pm 0.19$ ); these measurements were derived from the same individuals used in experiments. This balanced (1) the use of comparable body sizes of the two fish species to examine species-effects on feeding rates with minimal confounds of body size, but (2) was also a very conservative body size (and hence gape size and gut capacity) of the invader, which in the wild attains much greater size than the native (Fuller et al. 2007; Maitland and Campbell 1992).

Fish species were housed separately in opaque plastic tanks $(94 \mathrm{~cm} \times 63 \mathrm{~cm} \times 50 \mathrm{~cm})$ filled with $120 \mathrm{~L}$ of continually aerated dechlorinated tapwater, and were maintained on a diet of frozen chironomid larvae obtained from a commercial fish supplier to standardise prior experience with the prey species being tested (see Laverty et al. 2015). Prey species were held separately in glass tanks $(35 \mathrm{~cm} \times$ $26 \mathrm{~cm} \times 21 \mathrm{~cm}$ ) filled with $8 \mathrm{~L}$ of continually aerated dechlorinated tapwater; stream flora and fauna were 
added to provide food and habitat. We used amphipods and isopods of 3-5 mm and 4-6 mm total body length, respectively, for the experiments, as the fish species were observed to feed on these sizes readily and had no apparent gape height restrictions with such prey. The experimental room was maintained under a controlled $12 \mathrm{hL}: 12 \mathrm{hD}$ photoperiod, and ambient temperature ranged from 18 to $22{ }^{\circ} \mathrm{C}$.

FR experimental procedure

Trials took place in rectangular glass tanks $(35 \mathrm{~cm} \times 26 \mathrm{~cm} \times 21 \mathrm{~cm})$ filled with $8 \mathrm{~L}$ of dechlorinated tapwater which was aerated prior to use. White partitions were placed on all vertical sides of the tanks to obscure the view of the fish from each other and the human observers. Individual fish, starved for $24 \mathrm{~h}$ prior to experiments to standardize hunger levels, were introduced to tanks ( 1 fish per tank) and allowed to settle for $2 \mathrm{~h}$. Trials began upon introduction of the prey in densities of 2, 4, 8, 16,32, and 64 per tank, and fish were then left to feed undisturbed for $4 \mathrm{~h}$ (determined from pilots). Trials were terminated upon removal of the predator and remaining live prey counted. This was done on each of six days with twelve experimental tanks, fully randomised with respect to the treatments of 'predator species', 'prey species', 'prey density', thus giving $n=3$ per treatment combination. We ran controls of prey introductions to predator free tanks, identical but separate from experimental tanks, to account for any prey mortality from sources other than predators $(n=3$ per prey density). At the end of the experiments, fish were humanely euthanised in clove oil.

\section{Predator abundance estimates}

The Office National de l'Eau et des Milieux Aquatiques (ONEMA) supplied us with $N$. melanostomus and Cottus gobio density data from their electrofishing survey of the Moselle River at Contz-les-Bains (N49 $\left.{ }^{\circ} 5^{\prime} 21.36^{\prime \prime} \mathrm{E}^{\circ} 34^{\prime} 47.11\right)$. Hence, we used the density estimate of $N$. melanostomus as $0.25 \mathrm{ind} / \mathrm{m}^{2}$ (ONEMA 2013) and Cottus gobio as $0.008 \mathrm{ind} / \mathrm{m}^{2}$ (ONEMA 2011). Thus, we had density estimates of the two fish species from the same location, before and after the invasion and replacement of the native. We also found abundance data for Cottus gobio from Cowx and Harvey (2003) of $0.46 \pm 0.25 \mathrm{SE}$ ind $/ \mathrm{m}^{2}$.
Further, to combine with the FRs of $N$. melanostomus and Cottus bairdi from Dubs and Corkum (1996), we searched the literature and found density estimates for $N$. melanostomus of $14 \pm 0.26 \mathrm{SE}$ ind $/ \mathrm{m}^{2}$ (Barton et al. 2005) and Cottus bairdi of $0.87 \pm 0.11 \mathrm{SE}$ ind/ $\mathrm{m}^{2}$ (Petty and Grossman 2004). N. melanostomus is characerised by high densities across its invasive range (Marsden and Jude 1995).

Species collection and husbandry: Pseudorasbora parva and Rhodeus amarus

In August 2014, invasive Pseudorasbora parva were collected by electrofishing (Deka 3000) from three locations in Belgium; Zonhoven $\left(50^{\circ} 58^{\prime} 06^{\prime \prime} \mathrm{N}\right.$; $\left.5^{\circ} 20^{\prime} 58^{\prime \prime} \mathrm{E}\right)$, Kastel $\left(51^{\circ} 03^{\prime} 05^{\prime \prime} \mathrm{N} ; 4^{\circ} 11^{\prime} 23^{\prime \prime} \mathrm{E}\right)$ and Sint-Pieters-Leeuw $\left(50^{\circ} 47^{\prime} 01^{\prime \prime} \mathrm{N} ; 4^{\circ} 14^{\prime} 27^{\prime \prime} \mathrm{E}\right)$, while native Rhodeus amarus were obtained from Zwalm $\left(50^{\circ} 54^{\prime} 07^{\prime \prime} \mathrm{N} ; 3^{\circ} 42^{\prime} 40.9^{\prime \prime} \mathrm{E}\right)$. Both species were then transferred in source water to the Ghent University laboratory, Belgium, where experiments took place. Fish used in the experiment below were size matched as closely as possible with respect to total length (TL) and were all between 50 and $60 \mathrm{~mm}$. Daphnia magna were sourced from ecotoxological laboratory cultures at Ghent University, Belgium, where they were continually cultured. A microalgal infusion was added to the $D$. magna, ad libitum, as a food source, and juveniles were extracted using a series of stacked sieves (200 and 400 microns), resulting in individuals no greater than $0.2 \mathrm{~mm}$ in length. Frozen chironomid larvae (3-6 mm in length) were purchased commercially. Daphnia and chironomids were chosen as common prey items of these fish species (see Holker and Breckling 2001) and the invader and native fish ate these prey species readily in pilot trials. Fish species were housed separately in opaque plastic tanks $(50 \mathrm{~cm} \times 30 \mathrm{~cm} \times 40 \mathrm{~cm})$ filled with $100 \mathrm{~L}$ of continually aerated carbon-filtered dechlorinated tapwater, and were maintained on a diet of commercially available fish food (TetraMin(C) to standardise prior experience with the prey species being tested; stream flora and inanimate objects were added to provide habitat. The experimental room was maintained under a controlled 16hL: $8 \mathrm{hD}$ photoperiod, and ambient temperature maintained at $20( \pm 1)^{\circ} \mathrm{C}$. Fish were housed for one week prior to experiments commencing. After use in functional response experiments, individuals were transferred to separate longterm holding aquaria. 
FR experimental procedure

Trials took place in rectangular glass tanks $(35 \mathrm{~cm} \times 26 \mathrm{~cm} \times 21 \mathrm{~cm})$ filled with $13 \mathrm{~L}$ of dechlorinated tapwater which was aerated prior to use. Opaque partitions were placed on all vertical sides of the tanks to obscure the view of the fish from each other and the human observers. Individual fish, starved for $24 \mathrm{~h}$ prior to experiments (as above), were introduced to tanks (1 fish per tank) and allowed to settle for $2 \mathrm{~h}$. Trials began upon introduction of the prey in densities of $4,8,16,32$, 64 and 128 ( $n=3$ per density), with fish then left to feed undisturbed for $1 \mathrm{~h}$ (again based on pilots). Randomised replicates took place over 3 consecutive days. Trials were terminated upon removal of the predator and remaining live prey counted after being passed over stacked sieves (200 and 400 microns). We ran controls of prey introductions to predator free tanks to account for any prey mortality from sources other than predators ( $n=3$ per density).

Predator abundance estimates

Pseudorasbora parva density data were from our electrofishing survey of 3 ponds in Zonhoven $\left(50^{\circ} 58^{\prime} 06^{\prime \prime} \mathrm{N} ; 5^{\circ} 20^{\prime} 58^{\prime \prime} \mathrm{E}\right)$ and Rhodeus amarus from a pond in Zwalm $\left(50^{\circ} 54^{\prime} 07^{\prime \prime} \mathrm{N} ; 3^{\circ} 42^{\prime} 40.9^{\prime \prime} \mathrm{E}\right)$. Hence, we used the density estimate of P. parva as $1.6 \pm 0.39$ $\mathrm{SE}$ ind $/ \mathrm{m}^{2}$ and $R$. amarus (point density estimate only) as $0.088 \mathrm{ind} / \mathrm{m}^{2}$. P. parva is characterised by high densities across its invasive range (Declerck et al. 2002).

FR data analysis

Overall consumption of prey was compared with respect to 'predator species', 'prey species', and 'prey density' using generalised linear models (GLMs), assuming a quasipoisson error structure to account for overdispersion in the models (residual deviances were greater than degrees of freedom). A stepwise deletion procedure was used to remove non-significant terms and achieve the most parsimonious model (Crawley 2007). Functional response Type (I, II or III) was determined using logistic regression with respect to the proportion of prey consumed as a function of prey density; the Type II FR is characterised by a significantly negative first order coefficient, whereas the Type III FR is characterised by a significantly positive first order coefficient and significantly negative second order coefficient (Juliano 2001). Type II FRs were modelled using the 'random predator equation' (Rogers 1972), which accounts for depletion of prey as they are consumed without prey replacement (Juliano 2001):

$N_{e}=N_{0}\left(1-\exp \left(a\left(N_{e} h-T\right)\right)\right)$

where $N_{e}$ is the number of prey eaten, $N_{0}$ is the initial prey density, $a$ is the attack rate, $h$ is the handling time for each prey item and $T$ is the total time available; from these, the estimated maximum feeding rate $1 / h T$, can then be calculated. The model was fitted to the data using the Lambert W function (Bolker 2008) and multiple estimates of the parameter $h$ were generated using bootstrapping $(n=30)$ and $1 / h T$ calculated. This generated mean estimated maximum feeding rates \pm SE for comparative biplots (see below). Type III FRs were modelled using the Hassell's Type III response (not assuming prey replacement) (Hassell 1978):

$N_{e}=N_{0}\left(1-\exp \left(\left(d+b N_{0}\right)\left(\operatorname{Th} N_{e}-T\right) /\left(1+c N_{0}\right)\right)\right)$

where $N_{e}$ is the number of prey eaten, $N_{0}$ is the initial prey density, attack rate ' $a$ ' is derived from the equation: $a=(d+b N) /(1+c N)$ where $b, c$ and $d$ are constants, $h$ is the handling time and $T$ is the total time available; from these, the maximum feeding rate $1 / h T$, can then be calculated. Multiple estimates of the parameter $h$ were generated using bootstrapping $(n=30)$ and $1 / h T$ calculated. This generated mean estimated maximum feeding rates \pm SE for the RIP biplots (see below). All analyses were carried out in R (R Development Core Team 2012) and a significance threshold of $P<0.05$ was used throughout statistical testing. Finally, taking the mean maximum feeding rate and abundance estimates as above, we plotted the "RIP biplots" to represent the relative impact potential (RIP) of the invaders as compared to the natives (see below).

\section{Results}

Neogobius melanostomus and Cottus gobio

In controls, prey survival was $100 \%$, hence we assumed that all prey mortality in the experimental 
treatments was the result of predation by the fish. The invasive $N$. melanostomus consumed significantly more prey overall than did the native $C$. gobio (est. $=0.45, \quad t=4.6, \quad P<0.001 ;$ Fig. $1 \mathrm{a}-\mathrm{d}$ ), and significantly more Echinogammarus berilloni were consumed than Asellus aquaticus (est. $=0.49$, $t=5.1, P<0.001$; Fig. 1a-d). Prey consumption was significantly greater at higher prey densities (est. $=3.11, t=14.2, P<0.001$; Fig. 1a-d). The higher predation rate of $N$. melanostomus as compared to $C$. gobio was significantly more pronounced with $A$. aquaticus than E. berilloni, as evidenced by the significant 'predator species x prey species' interaction effect (est. $=0.34, t=2.7, P<0.01$; Fig. $1 \mathrm{a}-\mathrm{d}$ ); indeed, there was no significant difference in $E$. berilloni consumption between predator species (est. $=0.29, \quad t=1.3, \quad P=0.21$ ). All functional responses were Type II as revealed by the significant negative first order coefficient returned by logistic regression analysis (Table 1; Fig. 1). Mean estimated maximum feeding rates $( \pm \mathrm{SE})$ for the invasive fish towards both prey species were substantially higher compared to the native fish (see Table 2). On the RIP biplots (Fig. 2; Table 3), the FR/Abundance values for the invasive $N$. melanostomus are clearly shifted towards the top and right and those for the native $C$. gobio and $C$. bairdi towards the bottom and left, reflecting field impact.

\section{Pseudorasbora parva and Rhodeus amarus}

In controls, prey survival was $100 \%$, hence we assumed all prey mortality in the experimental treatments was the result of predation by the fish. The invasive $P$. parva consumed significantly fewer prey overall than did the native $R$. amarus (est. $=0.87$, $t=4.1, P<0.001$; Fig. 3a-d), and significantly more Daphnia magna were consumed than Chironomid larvae (est. $=1.3, t=6.4, P<0.001$; Fig. 3a-d). Prey consumption was significantly greater at higher
Fig. 1 Functional responses of invasive Neogobius melanostomus $(\mathbf{a}, \mathbf{b})$ and native Cottus gobio $(\mathbf{c}, \mathbf{d})$ toward Echinogammarus berilloni (a, c) and Asellus aquaticus (b, d). Data points are mean prey consumed \pm SE after 4 h. See Table 3 for colour legend
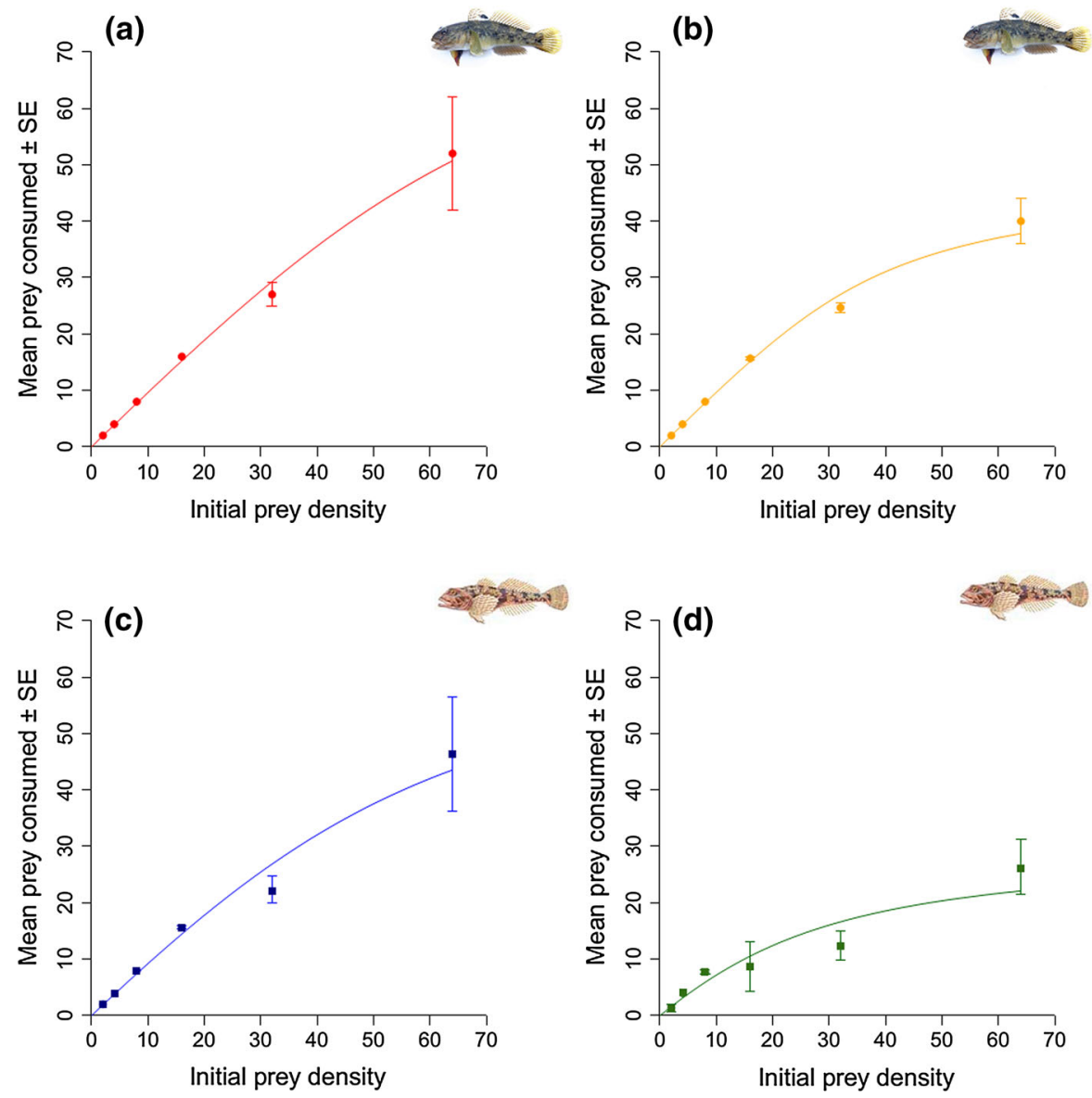
Table 1 First order linear coefficient results (lc) from logistic regressions for combinations predator and prey

\begin{tabular}{llll}
\hline Predator & Prey & Linear coefficient & $P$ value \\
\hline Neogobius melanostomus & Echinogammarus berilloni & -5.084 & $<0.001$ \\
& Asellus aquaticus & -5.117 & $<0.001$ \\
Cottus gobio & Echinogammarus berilloni & -5.529 & $<0.001$ \\
& Asellus aquaticus & -6.005 & $<0.001$ \\
Pseudorasbora parva & Chironomid spp. & 2.08 & $<0.05$ \\
\multirow{2}{*}{ Rhodeus amarus } & Daphnia magna & 4.406 & $<0.001$ \\
& Chironimid spp. & -6.56 & $<0.001$ \\
& Daphnia magna & 5.732 & $<0.001$ \\
\hline
\end{tabular}

Table 2 Maximum feeding rate values for each predator and prey combination. Maximum feeding rates are mean $\pm \mathrm{SE}$

\begin{tabular}{lll}
\hline Predator & Prey & Maximum feeding rate \pm SE \\
\hline Neogobius melanostomus & Echinogammarus berilloni & $128.4 \pm 22.48$ \\
& Asellus aquaticus & $48.75 \pm 1.52$ \\
& Gammarus & 0.17 \\
Cottus gobio & Echinogammarus berilloni & $71.37 \pm 9.81$ \\
& Asellus aquaticus & $44.71 \pm 9.84$ \\
Cottus bairdi & Gammarus & 0.12 \\
Pseudorasbora parva & Chironomid spp. & $25.3 \pm 2.95$ \\
& Daphnia magna & $118 \pm 0.86$ \\
Rhodeus amarus & Chironimid spp. & $51.3 \pm 10.24$ \\
& Daphnia magna & $127.3 \pm 0.21$ \\
\hline
\end{tabular}

prey densities (est. $=3.54, \quad t=8.2, \quad P<0.001$; Fig. 3a-d). The higher predation rate of $R$. amarus as compared to $P$. parva was significantly more pronounced with chironomid larvae than D. magna, as evidenced by the significant 'predator species $\mathrm{x}$ prey species' interaction effect (est. $=0.59, t=2.4$, $P<0.05$; Fig. 3a-d). R. amarus functional responses toward chironimid spp. were Type II, while $P$. parva functional responses toward chironomid spp. were Type III as revealed by the significant negative and positive first order coefficients respectively returned by logistic regression analysis (Table 1; Fig. 3), while all functional responses toward D. magna were Type III as revealed by positive first order coefficients returned by logistic regression (Table 1; Fig. 3). Mean estimated maximum feeding rates $( \pm \mathrm{SE})$ for the invasive fish towards both prey species were lower compared to the native fish (see Table 2). On the RIP biplots (Fig. 4; Table 4), however, the values for the invasive $P$. parva again are clearly shifted towards the top and right and those for the native $R$. amarus towards the bottom and left, reflecting actual field impact.

\section{Discussion}

Predicting the ecological impacts of invasive species is notoriously difficult (Ricciardi et al. 2013), with species-trait based approaches to impact prediction largely unsuccessful to date (Dick et al. 2014). However, recent comparisons of invader and native functional responses (FRs) have often yielded excellent explanatory and predictive power of invader impact on native prey populations (Alexander et al. 2014a, b; Dick et al. 2013, 2014, 2017), and this has recently been extended to damaging herbivorous invaders (e.g. golden apple snail; Xu et al. 2016). Indeed, the method is applicable to any taxonomic or trophic group due to the universal nature of organisms utilizing resources (Dick et al. 2017). The comparative FR method has also allowed the incorporation of context-dependencies, once viewed as a serious impediment to impact prediction, for example, by highlighting how differential impacts of invasive and native predators on prey populations are likely to change under altered abiotic and biotic regimes (e.g. habitat complexity: Alexander et al. 2014a, oxygen 
Fig. 2 RIP biplots (see also Table 3) of invasive Neogobius melanostomus (red, orange and black filled circle and black filled triangle) and native Cottus gobio (green and blue filled squares and stars) and native Cottus bairdi (black open diamond). Triangles and stars indicate ONEMA abundance data, circles, squares and diamonds indicate abundance data from Barton et al. (2005), Cowx and Harvey (2003) and (Petty and Grossman 2004). FR data for Neogobius melanostomus and Cottus bairdi were also sourced from Dubs and Corkum (1996). Means are $\pm \mathrm{SE}$, except abundances from ONEMA. Ecological impact increases from bottom left to top right

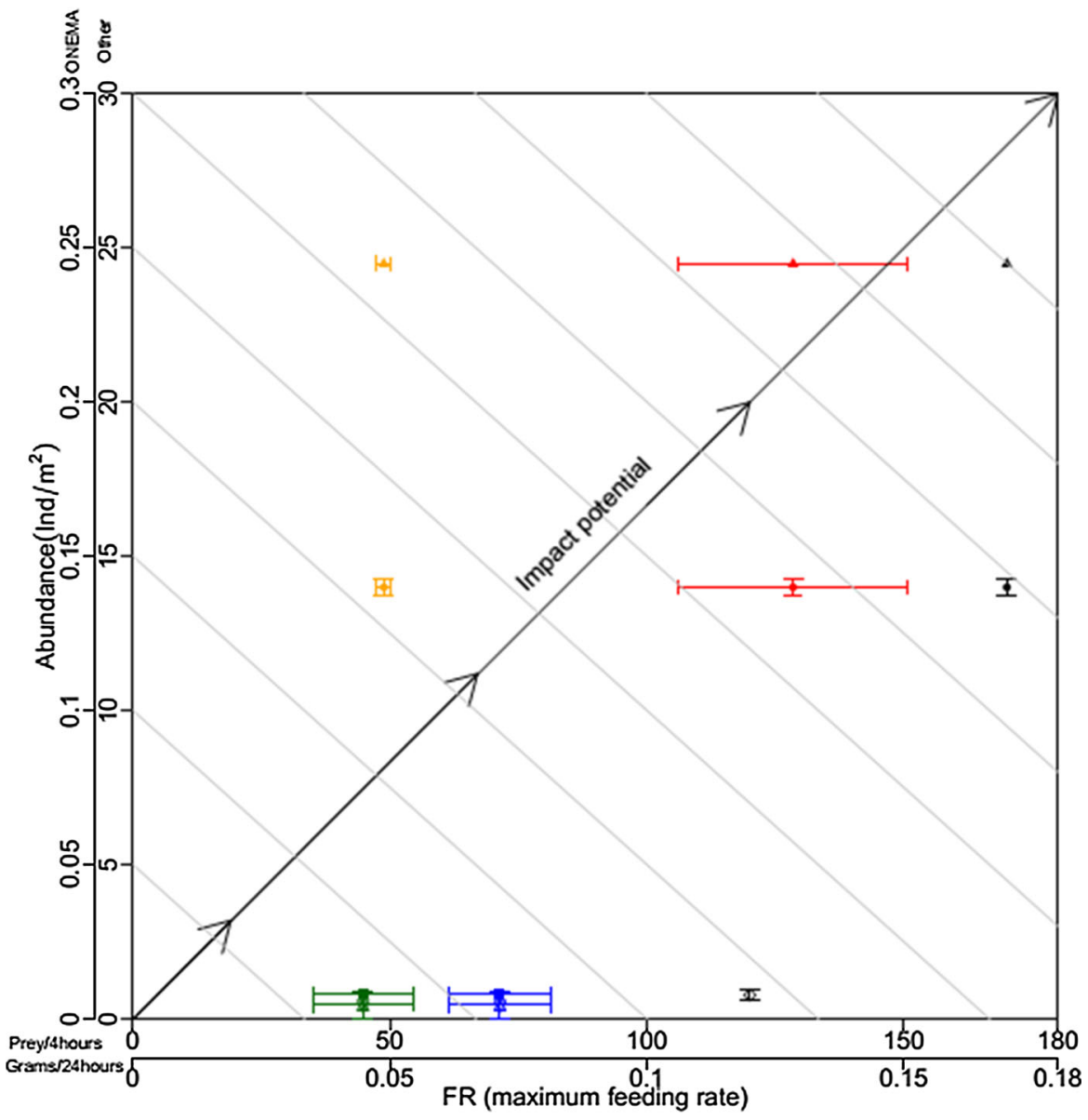

availability: Laverty et al. 2015; multiple predators: Barrios-O'Neill et al. 2014a, b, 2015). Although the incorporation of such context-dependencies can help with impact prediction, simple laboratory experiments that do not necessarily mimic natural conditions are often suffice to produce meaningful and highly predictive comparative functional respsonses. For example, such an approach revealed that the magnitude of difference between invader and native FRs was correlated with actual field impacts of the bloody red shrimp Hemymysis anomala (Dick et al. 2013). Thus, FRs provide mechanistic explanations of impact, that is, measurable features of individuals and their interactions with resources (Dick et al. 2017).

In the present study, we demonstrate that comparing FRs of the ecologically damaging invasive goby Neogobius melanostomus with the native comparator Cottus gobio toward two prey species, Echinogammarus berilloni and Asellus aquaticus, is again predictive of invader ecological impact. Overall, $N$. melanostomus consumed greater numbers of prey than did C. gobio, which is indicative of its impact on native communities (Barton et al. 2005; Pagnucco and Ricciardi 2015) and may allow impact prediction prior to it invading a naïve native community (Dick et al. 2013, 2014). Both predators consumed significantly more of the gammarid, E. berilloni, than the isopod, $A$. aquaticus, but the latter prey species was disproportionately affected by predation from $N$. melanostomus. Indeed, there was no significant difference in $N$. melanostomus and $C$. gobio actual predation of Echinogammarus berilloni, although estimated maximum feeding rates from FRs were higher for the invader. N. melanostomus is a voracious predator of both gammarids and isopods (Corkum et al. 2004), with this partially borne out in the present study, indicating the suitability of the FR method in predicting the impact of $N$. melanostomus on naïve native $A$. 
Table 3 Colours and symbols for each predator and prey species combination displayed in Fig. 2 RIP biplots

\begin{tabular}{|c|c|c|c|c|}
\hline & \multicolumn{2}{|c|}{$\begin{array}{c}\text { Invader (Round goby) } \\
\text { (Neogobius melanostomus) }\end{array}$} & \multicolumn{2}{|c|}{$\begin{array}{c}\text { Native (European Bullhead) } \\
\text { (Cottus gobio) }\end{array}$} \\
\hline \multirow{2}{*}{$\begin{array}{l}\text { Source of predator } \\
\text { abundance estimates }\end{array}$} & \multicolumn{2}{|c|}{ Prey species } & \multicolumn{2}{|c|}{ Prey species } \\
\hline & $\begin{array}{c}\text { Echinogammarus } \\
\text { berilloni }\end{array}$ & $\begin{array}{c}\text { Asellus } \\
\text { aquaticus }\end{array}$ & $\begin{array}{c}\text { Echinogammarus } \\
\text { berilloni }\end{array}$ & $\begin{array}{c}\text { Asellus } \\
\text { aquaticus }\end{array}$ \\
\hline ONEMA & $\Delta$ & $\Delta$ & $\star$ & $\star \Delta$ \\
\hline \multirow{2}{*}{$\begin{array}{l}\text { Barton et al. (2005)/Cowx } \\
\text { \& Harvey (2003) }\end{array}$} & $\bullet$ & - & घ & n \\
\hline & \multicolumn{2}{|c|}{$\begin{array}{c}\text { Invader (Round goby) } \\
\text { (Neogobius melanostomus) }\end{array}$} & \multicolumn{2}{|c|}{$\begin{array}{l}\text { Native (Mottled sculpin) } \\
\text { (Cottus bairdi) }\end{array}$} \\
\hline $\begin{array}{l}\text { Sources of predator } \\
\text { abundance estimates }\end{array}$ & \multicolumn{2}{|c|}{ Prey species } & \multicolumn{2}{|c|}{ Prey species } \\
\hline ONEMA & \multicolumn{2}{|c|}{ Gammarus spp. } & \multicolumn{2}{|c|}{$\begin{array}{l}\text { Gammarus spp. } \\
\text { NA }\end{array}$} \\
\hline $\begin{array}{l}\text { Barton et al. (2005)/Petty } \\
\text { and Grossman (2004) }\end{array}$ & \multicolumn{2}{|c|}{$\bullet$} & \multicolumn{2}{|c|}{$\Delta$} \\
\hline
\end{tabular}

aquaticus communities. However, only moderate impact would be predicted on E. berilloni using the FR method; indeed the overall differences in numbers of prey eaten by $N$. melanostomus and C. gobio found here, whilst significant, do not match well with the known extremely high impact of the invader on native macroinvertebrate and fish communities (Barton et al. 2005; Pagnucco and Ricciardi 2015). We show, however, that an improvement in impact prediction is attained when ecologically comparable abundances of the invader and native are taken into account in the Relative Impact Prediction (RIP) biplots, which capture both the per capita predator effects (i.e. interaction presence and strength) and the number of individuals engaging in predation. The RIP method also worked well for $N$. melanostomus when compared to another native, Cottus bairdi, with FR and abundance data sourced from the literature; that is, the biplots for the invader were located more to the top and right (high impact) and the native more to the bottom and left (low impact). These invader/native differences are in fact likely to be conservative, since the invader typically reaches larger size classes compared to the native (see also Dodd et al. 2014). Additionally, however, the RIP method could capture reductions in the impact of the invader as co-evolutionary forces manifest in, for example, reduced naiveté of the prey over time, as evidenced by lower functional responses. The abundance of the invader may also decline over time and again this could be captured in the RIP biplots.

Further, we investigated the FRs of the invasive Pseudorasbora parva and the native Rhodeus amarus toward two prey species, chironomid spp. and Daphnia magna. Despite overwhelming evidence that $P$. parva is a highly damaging invader (Britton et al. 2010; Gozlan et al. 2010), the FR of P. parva was significantly lower overall than that of $R$. amarus. Again, however, the RIP metric, by incorporating the abundances of the invader and native, clearly provides high explanatory and predictive power with respect to the ecological impact of this invader. This is because RIP captures both the presence and strength of the per capita interaction and also the number of individuals participating in that interaction.

It is thus clear from these two invasion examples that the biplots reveal that, where an invader has both a high FR and high abundance compared to natives, then high impact is predicted. However, where either FRs or abundances are relatively low for invaders, the higher value of the other parameter compensates for this and predicts high impact. For example, when round goby have lower abundance than the native comparator, the higher FR of the invader leads to a 
Fig. 3 Functional responses of invasive Pseudorasbora parva (a, b) and native Rhodeus amarus $(\mathbf{c}, \mathbf{d})$ towards chironomid spp. (a, c) and Daphnia magna $(\mathbf{b}, \mathbf{d})$. Data points are mean prey consumed $\pm \mathrm{SE}$ after $1 \mathrm{~h}$. See Table 4 for colour legend
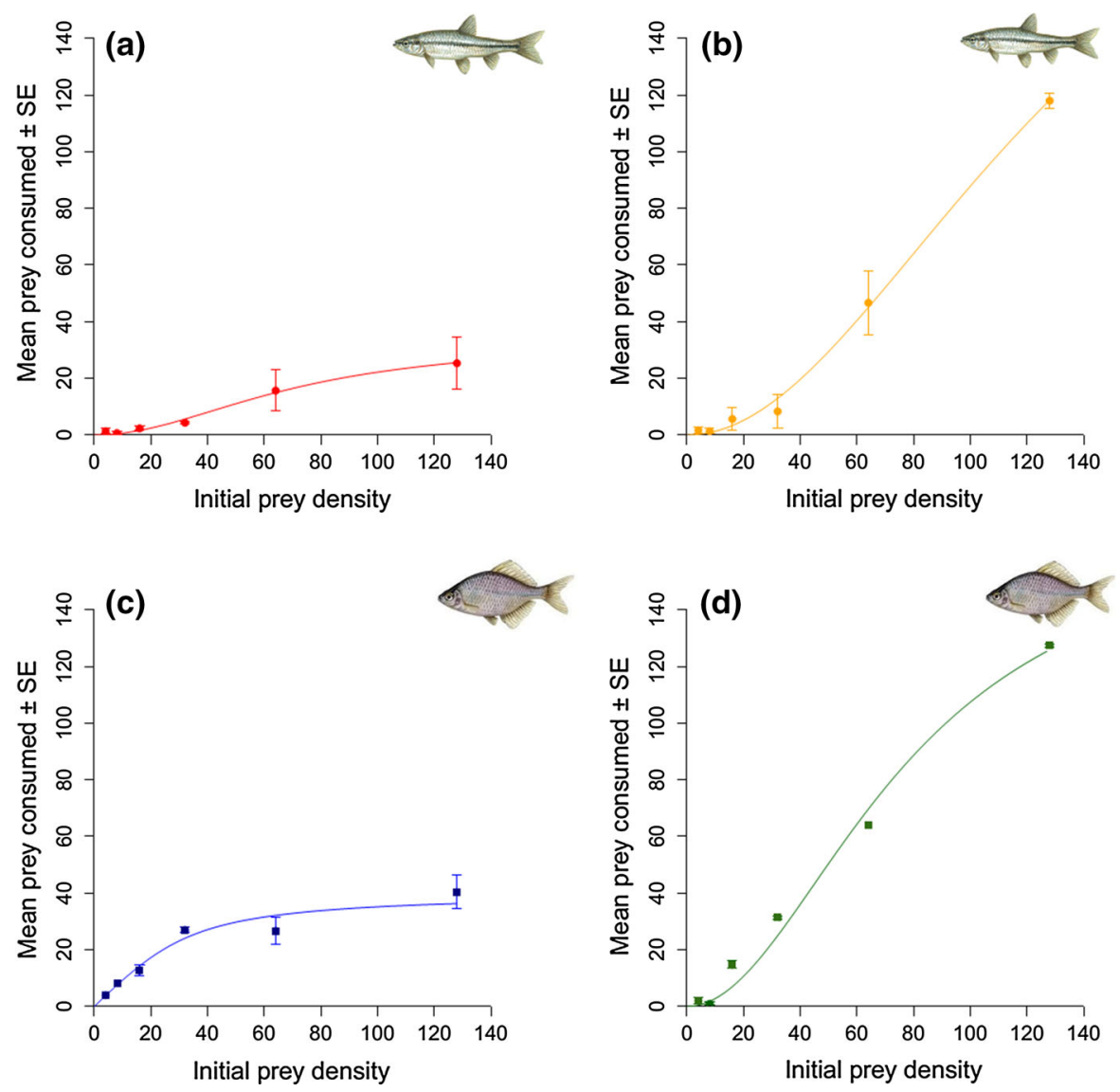

higher RIP; and where the topmouth gudgeon has a lower FR than the native comparator, the higher abundance of the invader leads to a higher RIP. This illustrates the requirement for both per capita and abundance estimates in assessing invader impact.

Parker et al. (1999) pointed out that the overall impact of an invader would be the product of per capita effects, abundance and range. This is similar to the "total response" metric as the product of "functional" and "numerical" responses (Dick et al. 2014). The current RIP metric blends these approaches with the functional response, which quantifies the presence and strength of the individual interaction of predator with prey, and the number of those prey engaging in the interaction, that is, simple field abundance estimates. This can capture not only the likelihood of any invasive species being ecologically damaging, but also perhaps the degree of ecological damage, as the offtake rate of prey by invader as compared to native can be calculated and visualised. We stress that, even although abundance is often high for invasive species, as was the case in the present study, this alone cannot be reliable in determining ecological impact. This is because there must be interaction(s) between the invader and the native community members, that is, there must be a per capita interaction to some degree-simple abundance cannot reliably predict impact (see Ricciardi and Cohen 2007). For example, highly distributed and abundant introduced species can have no detectable impact on native species (e.g. freshwater jellyfish Craspedacusta sowerbyi: Spadinger and Meier 1999; goldfish Carassius auratus: Fuller 2006; amphipod Crangonyx pseudogracilis: Dunn 2013; isopod Cirolana harfordi: Bugnot et al. 2014).

We appreciate that the abundance of a species is highly context dependent and that the RIP metric is highly sensitive to this part of the metric. However, here we had abundances of the native Cottus gobio and invader Neogobius melanostomus from the same site before and after the invader replaced the native, giving excellent (if not perfect) comparative data for the RIP. 
Fig. 4 RIP biplot (see also Table 4) of invasive Pseudorasbora parva (red and orange filled circles) and native Rhodeus amarus (blue and green filled squares). Mean $\pm \mathrm{SE}$, except abundances for Rhodeus amarus. Ecological impact increases from bottom left to top right

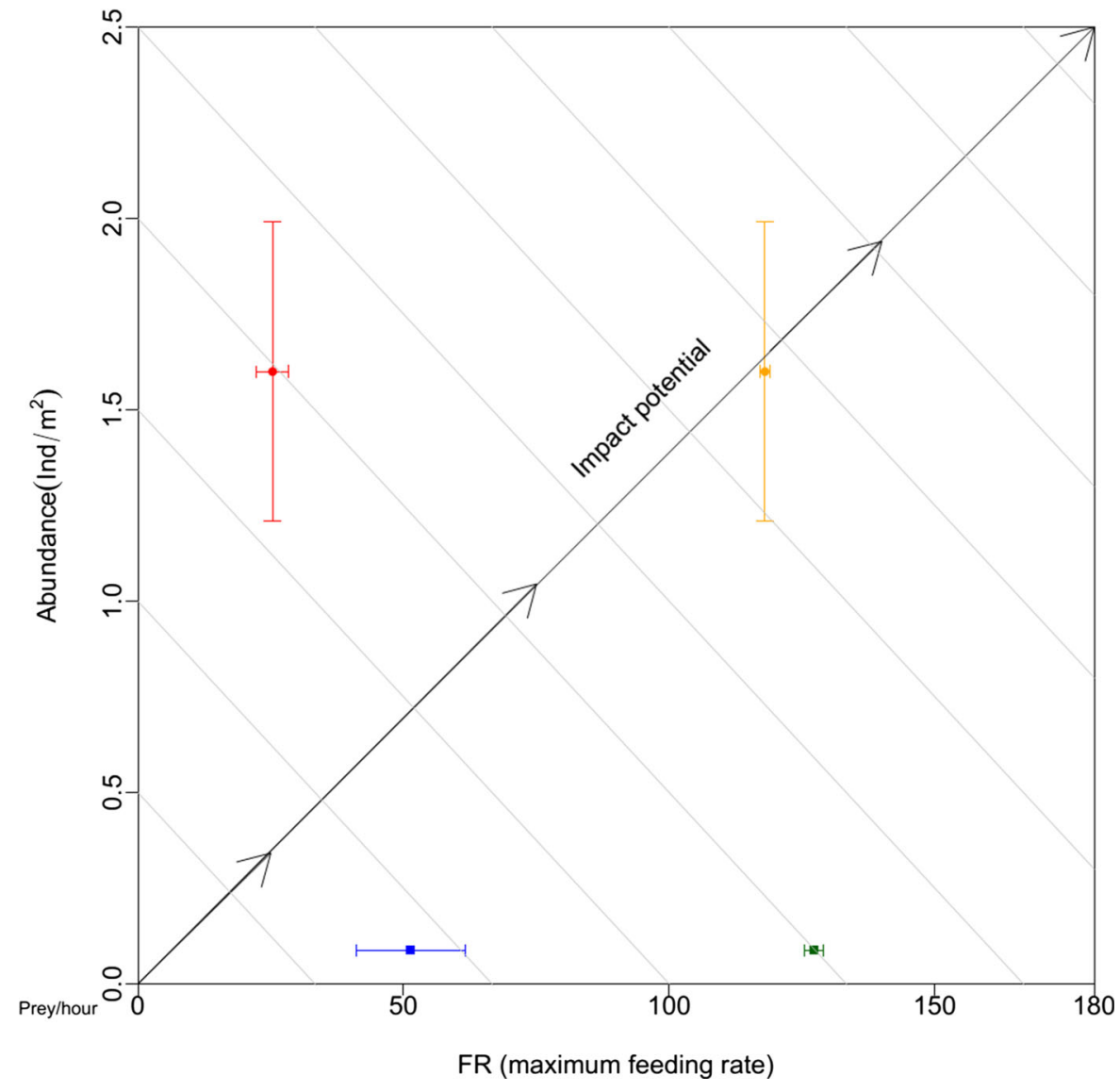

Table 4 Colours and symbols for each predator and prey species combination displayed in Fig. 4 RIP biplots

\begin{tabular}{|c|c|c|c|c|}
\hline \multirow{3}{*}{$\begin{array}{l}\text { Predator abundance } \\
\text { estimates }\end{array}$} & \multicolumn{2}{|c|}{$\begin{array}{l}\text { Invader (Top mouth Gudgeon) } \\
\text { (Pseudorasbora parva) }\end{array}$} & \multicolumn{2}{|c|}{$\begin{array}{l}\text { Native (Bitterling) } \\
\text { (Rhodeus amarus) }\end{array}$} \\
\hline & \multicolumn{2}{|c|}{ Prey species } & \multicolumn{2}{|c|}{ Prey species } \\
\hline & Chironomid spp. & $\begin{array}{c}\text { Daphnia } \\
\text { magna }\end{array}$ & Chironomid spp. & $\begin{array}{c}\text { Daphnia } \\
\text { magna }\end{array}$ \\
\hline Present study & $\bullet$ & • & घ & घ \\
\hline
\end{tabular}

Further, we used available data from the field across a number of invader and native fishes and the literature also suggests the higher abundances in general of the invaders. Together with the FR data that indicate the presence and strength of the interactions of the fishes with the broader community members, this gave RIP biplots that reflect reality, that is, the known field ecological impacts of the invaders. By incorporating more data on both FRs and abundances under differing context dependencies, the RIP biplot method could be advanced such that both the identities of invaders and degree of their ecological impacts under contexts (e.g. warming) could be attained. Further, once RIP is calculated for a greater range of invasion scenarios (and taxa/trophic groups), at differing spatio-temporal scales and across abiotic and biotic contexts, its general utility and reliability in impact prediction can be better determined. 


\section{Conclusion}

Recent studies (e.g. Alexander et al. 2014a, b; Dick et al. 2013, 2017; Paterson et al. 2014; Laverty et al. 2015; Xu et al. 2016) have shown that the comparative FR methodology is rapid, efficient and effective at explaining and predicting the ecological damage caused by invasive species. However, in some cases the FR of invasive species is unremarkable when compared to those of native species, yet ecological damage is known to occur, as is the case with $N$. melanostomus and $P$. parva toward invaded communities (Barton et al. 2005; Britton et al. 2010; Gozlan et al. 2010; Pagnucco and Ricciardi 2015). When the abundances as well as FRs of invasive and native species are included in the "Relative Impact Potential" assessment, the overall forecast of impact is better reconciled with known field impacts. Our RIP biplots also allows for a clear visual comparison of the impact of multiple invaders in relation to their native comparators; such a straightforward methodology could allow for rapid risk assessment and prioritisation of potentially damaging invaders as, for example, is now required by recent EU legislation (EU Regulation No. 1143/2014) governing the management of invasive species (see also Caffrey et al. 2014).

Acknowledgements This study was funded by a short-term scientific mission (STSM) grant from COST Action TD1209, and forms part of two Ph.D. studentships funded by Queen's University Belfast, Institute of Technology Sligo, Inland Fisheries Ireland and the Department of Employment and Learning. For the experiments completed in France, we acknowledge Sébastien Manné, Nicolas Poulet and Samuel Dembski from the ONEMA, and the support of the ANR program "Investissement d'avenir: Equipement d'excellence" (ANR PLANAQUA 10-EQPX-13-01) coordinated by the CEREEP field station.

Open Access This article is distributed under the terms of the Creative Commons Attribution 4.0 International License (http:// creativecommons.org/licenses/by/4.0/), which permits unrestricted use, distribution, and reproduction in any medium, provided you give appropriate credit to the original author(s) and the source, provide a link to the Creative Commons license, and indicate if changes were made.

\section{References}

Alexander ME, Kaiser H, Weyl OLF, Dick JTA (2014a) Habitat simplification increases the impact of a freshwater invasive fish. Environ Biol Fish 98:477-486
Alexander ME, Dick JTA, Weyl OLF, Robinson TB, Richardson DM (2014b) Existing and emerging high impact invasive species are characterized by higher functional responses than natives. Biol Letts 10:20130946

Barrios-O'Neill D, Dick JTA, Emmerson MC, Ricciardi A, Macisaac HJ, Alexander ME, Bovy HC (2014a) Fortune favours the bold: a higher predator reduces the impact of a native but not an invasive intermediate predator. J Anim Ecol 83:693-701

Barrios-O’Neill D, Dick JTA, Ricciardi A, MacIsaac HJ, Emmerson MC (2014b) Deep impact: in situ functional responses reveal context-dependent interactions between vertically migrating invasive and native mesopredators and shared prey. Freshw Biol 59:2194-2203

Barrios-O’Neill D, Dick JTA, Emmerson MC, Ricciardi A, MacIsaac HJ (2015) Predator-free space, functional responses and biotic resistance towards invasive species. Funct Ecol 29:377-384

Barton DR, Johnson RA, Campbell L, Petruniak J, Patterson M (2005) Effects of round gobies (Neogobius melanostomus) on dreissenid mussels and other invertebrates in Eastern Lake Erie, 2002-2004. J Great Lakes Res 31:252-261

Bolker BM (2008) Emdbook: ecological models and data in R, R Package. Princeton University Press, Princeton

Britton JR, Davies GD, Harrod C (2010) Trophic interactions and consequent impacts of the invasive fish Pseudorasbora parva in a native aquatic foodweb: a field investigation in the UK. Biol Invasions 12:1533-1542

Bugnot AB, Coleman RA, Figueira WF, Marzinelli EM (2014) Patterns of the non-indigenous isopod Cirolana harfordi in Sydney harbour. PLoS ONE 9(1):e86765. doi:10.1371/ journal.pone.0086765

Caffrey JM, Baars J-R, Barbour JH, Boets P, Boon P, Davenport $K$ et al (2014) Tackling invasive alien species in Europe: the top 20 issues. Manage Biol Invasions 5:1-20

Corkum LD, Sapota MR, Skora KE (2004) The round goby, Neogobius melanostomus, a fish invader on both sides of the Atlantic Ocean. Biol Invasions 6:173-181

Cowx IG, Harvey JP (2003) Monitoring the Bullhead, Cottus gobio. Conserving natura 2000 rivers monitoring series No. 4, English nature, Peterborough

Crawley MJ (2007) The R Book. John Wiley, Chichester

Declerck S, Louette G, De Bie T, De Meester L (2002) Patterns of diet overlap between populations of non-indigenous and native fishes in shallow ponds. J Fish Biol 6:1182-1197

Dick JTA, Gallagher K, Avlijas S, Clarke HC, Lewis SE, Leung $S$ et al (2013) Ecological impacts of an invasive predator explained and predicted by comparative functional responses. Biol Invasions 15:837-846

Dick JTA, Alexander ME, Jeschke J, Ricciardi A, MacIsaac H, Robinson T et al (2014) Advancing impact prediction and hypothesis testing using a comparative functional response approach. Biol Invasions 16:735-753

Dick JTA, Alexander ME, Ricciardi A, Laverty C, Downey PO, Xu M, Jeschke JM, Saul W-C, Hill MP, Wasserman R, Barrios-O'Neill D, Weyl OLF, Shaw RH (2017) Functional responses can unify invasion ecology. Biol Invasions doi:10.1007/s10530-016-1355-3

Dodd JA, Dick JTA, Alexander ME, MacNeil C, Dunn AM, Aldridge DC (2014) Predicting the ecological impacts of a 
new freshwater invader: functional responses and prey selectivity of the 'killer shrimp', Dikerogammarus villosus, compared to the native Gammarus pulex. Freshw Biol 59:337-352

Dubs DOL, Corkum LD (1996) Behavioral interactions between round gobies (Neogobius melanostomus) and mottled sculpins (Cottus bairdi). J Great Lakes Res 22:838-844

Dunn A (2013) GB Non-native organism risk assessment for Crangonyx pseudogracilis. www.nonnativespecies.org

Fuller P (2006) Non-indigenous aquatic species (NAS) Database. Retrieved from http://nas.er.usgs.gov/ on 27 June 2016

Fuller P, Benson A, Maynard E (2007) “Apollonia (Neogobius) melanostomus" (On-line). USGS nonindigenous aquatic species database. Accessed June, 2016 at http://nas.er.usgs. gov/queries/FactSheet.asp?speciesID=713

Gozlan RE, Andreou D, Asaeda T, Beyer K, Bouhadad R, Burnard D et al (2010) Pan-continental invasion of Pseudorasbora parva: towards a better understanding of freshwater fish invasions. Fish Fisheries 11:315-340

Hassell MP (1978) Functional responses. In: Hassell MP (ed) The dynamics of arthropod predator-prey systems. Princeton University Press, Princeton, pp 28-49

Holker F, Breckling B (2001) An individual-based approach to depict the influence of the feeding strategy on the Population Structure of Roach (Rutilus rutilus L.). Limnol 31:69-78

Holling CS (1959a) Some characteristics of simple types of predation and parasitism. Can Entomol 91:38-398

Holling CS (1959b) The components of predation as revealed by a study of small-mammal predation of the European pine sawfly. Can Entomol 91:293-320

Jude DJ, Reider RH, Smith GR (1992) Establishment of Gobiidae in the great lakes basin. Can J Fish Aqua Sci 49:416-421

Juliano SA (2001) Nonlinear curve fitting: predation and functional response curves. In: Scheiner SM, Gurevitch J (eds) Design and analysis of ecological experiments. Oxford University Press, Oxford, pp 178-196

Kulhanek SA, Ricciardi A, Leung SB (2011) Is invasion history a useful tool for predicting the impacts of the world's worst aquatic invasive species? Ecol Appl 21:189-202

Laverty C, Dick JTA, Alexander ME, Lucy FE (2015) Differential ecological impacts of invader and native predatory freshwater amphipods under environmental change are revealed by comparative functional responses. Biol Invasions 17(6): 1761-1770

Maitland PS, Campbell RN (1992) Freshwater fishes of the british isles. Harper Collins, London, p 368

Manné S, Poulet N, Dembski S (2013) Colonisation of the Rhine basin by non-native gobiids: an update of the situation in France. Knowl Manage Aqua Eco 411:02
Marsden JE, Jude DJ (1995) Round gobies invade North America. Fact sheet produced by Sea Grant at Ohio State University, Columbus

Pagnucco KS, Ricciardi A (2015) Disentangling the influence of abiotic variables and a non-native predator on freshwater community structure. Ecosphere 6: article 285

Parker IM, Simberloff D, Lonsdale WM, Goodell K, Wonham M, Kareiva PM, Williamson MH, Von Holle B, Moyle PB, Byers JE, Goldwasser L (1999) Impact: toward a framework for understanding the ecological effects of invaders. Biol Invasions 1:3-19

Paterson RA, Dick JTA, Pritchard DW, Ennis M, Hatcher MJ, Dunn AM (2014) Predicting invasive species impacts: a community module functional response approach reveals context dependencies. J Anim Ecol 84:453-463

Petty JT, Grossman GD (2004) Restricted movement by mottled sculpin (pisces: cottidae) in a southern Appalachian stream. Freshw Biol 49:631-645

Regulation (EU) No 1143/2014 of the European Parliament and of the Council of 22 (2014) On the prevention and management of the introduction and spread of invasive alien species. Off J Eur Union L315:35-55

Ricciardi A, Cohen J (2007) The invasiveness of an introduced species does not predict its impact. Biol Invasions 9:309-315

Ricciardi A, Hoopes MF, Marchetti MP, Lockwood JL (2013) Progress toward understanding the ecological impacts of nonnative species. Ecol Monogr 83:263-282

Rogers D (1972) Random search and insect population models. J Anim Ecol 41:369-383

Simberloff D, Martin J-L, Genovesi P, Maris V, Wardle DA, Aronson J, Courchamp F, Galil B, Garcia-Berthou E, Pascal M, Pysek P, Sousa R, Tabacchi E, Vila M (2013) Impacts of biological invasions: what's what and the way forward. Trends Ecol Evol 28:58-66

Solomon ME (1949) The natural control of animal populations. J Anim Ecol 18:1-35

Spadinger R, Maier G (1999) Prey selection and diel feeding of the freshwater jellyfish, Craspedacusta sowerby. Freshw Biol 41:567-573

Welton JA, Mills CA, Pygott JR (1991) The effect of interaction between stone loach Noemacheilus barbatulus (L.) and the bullhead Cottus gobio (L.) on prey and habitat selection. Hydrobiol 220:1-7

Xu M, Mu X, Dick JTA, Fang M, Gu D, Luo D et al (2016) Comparative functional responses predict the invasiveness and ecological impacts of alien herbivorous snails. PLoS ONE 11:e0147017 